\title{
Genetic variant rs4072037 of MUC1 and gastric cancer risk in an Eastern Chinese population
}

\author{
Li-Xin Qiu ${ }^{1,2, *}$, Rui-Xi Hua ${ }^{3, *}$, Lei Cheng ${ }^{2, *}$, Jing $\mathrm{He}^{4}$, Meng-Yun Wang ${ }^{2}$, Fei Zhou ${ }^{2}$, \\ Xiao-Dong Zhu ${ }^{1}$, Meng-Hong Sun ${ }^{5}$, Xiao-Yan Zhou ${ }^{5}$, Jin Li $^{1}$, Ya-Nong Wang ${ }^{6}$, \\ Ya-Jun Yang7,8, Jiu-Cun Wang7,8, Li Jin ${ }^{7,8}$, Wei-Jian Guo ${ }^{1}$, Qing-Yi Wei ${ }^{2,9}$ \\ ${ }^{1}$ Department of Medical Oncology, Fudan University Shanghai Cancer Center, Department of Oncology, Shanghai Medical \\ College, Fudan University, Shanghai, China \\ ${ }^{2}$ Cancer Institute, Collaborative Innovation Center for Cancer Medicine, Fudan University Shanghai Cancer Center, Shanghai, \\ China \\ ${ }^{3}$ Department of Oncology, The First Affiliated Hospital of Sun Yat-Sen University, Guangzhou, China \\ ${ }^{4}$ Department of Pediatric Surgery, Guangzhou Women and Children's Medical Center, Guangzhou Medical University, \\ Guangzhou, Guangdong, China \\ ${ }^{5}$ Department of Pathology, Fudan University Shanghai Cancer Center, Shanghai, China \\ ${ }^{6}$ Department of Gastric Cancer and Soft Tissue Sarcoma Surgery, Fudan University Shanghai Cancer Center, Shanghai, China \\ ${ }^{7}$ Ministry of Education Key Laboratory of Contemporary Anthropology and State Key Laboratory of Genetic Engineering, \\ School of Life Sciences, Fudan University, Shanghai, China \\ ${ }^{8}$ Fudan-Taizhou Institute of Health Sciences, Taizhou, Jiangsu, China \\ ${ }^{9}$ Duke Cancer Institute, Duke University Medical Center and Department of Medicine, Duke University School of Medicine, \\ Durham, NC, USA \\ *These authors contributed equally to this work
}

Correspondence to: Wei-Jian Guo, e-mail: guoweijian1@sohu.com Qing-Yi Wei, e-mail: weiqingyi@yahoo.com and qingyi.wei@duke.edu

Keywords: gastric cancer, genetic susceptibility, MUC1, polymorphism

Received: November 22, 2015

Accepted: Febraury 09, 2016

Published: February 20, 2016

\section{ABSTRACT}

Published data on the association between the MUC1 rs4072037A > G polymorphism and gastric cancer (GCa) risk were inconclusive. To derive a more precise estimation of the association, we conducted a large GCa study of 1,124 cases and 1,192 controls to confirm this association in an Eastern Chinese population. Our results showed that the $\mathrm{G}$ allele was strongly associated with a decreased GCa risk in the study population [GG vs. AA, odds ratio $(O R)=0.47,95 \%$ confidence interval $(\mathrm{CI})=0.31-0.73 ; \mathrm{AG} / \mathrm{GG}$ vs. AA, OR $=0.82,95 \% \mathrm{CI}=0.68-0.99 ; \mathrm{GG}$ vs. AA/AG, OR $=0.48,95 \% \mathrm{CI}=0.32-0.74]$. These associations remained significant in subgroups of age, tumor site, drinking and smoking status. Moreover, this association was supported by an additional meta-analysis of published studies. In summary, these results suggest that the MUC1 rs4072037G allele may be a low-penetrating protection factor for GCa risk in Chinese populations.

\section{INTRODUCTION}

Gastric cancer $(\mathrm{GCa})$ is one of the most common cancers and one of the leading causes of cancer-related deaths in the world. There were 951,600 new GCa cases and 723,100 deaths in 2012 , accounting for $8 \%$ of the cancer cases and $10 \%$ of cancer deaths, respectively [1]. Therefore, $\mathrm{GCa}$ is a major public health problem whose mechanism of carcinogenesis is still not fully understood. It is well- known that environmental factors and low-penetrance susceptibility genes may be important in the etiology of GCa. For example, a higher rate of Helicobacter pylori $(H P)$ infection $(70-90 \%)$ in developing countries than in developed countries $(25-50 \%)$ may have increased GCa risk in developing countries [2, 3]. However, not all $H P$ carriers will develop $\mathrm{GCa}$, suggesting that other factors are also important in the etiology, such as tobacco smoking, alcohol use and dietary habits [4]. In addition, genetic 
factors for the GCa risk are important as well, because the success in identifying at-risk populations by associations between genetic variants and GCa risk is encouraging [5-8]; however, it is necessary to confirm those genetic factors that have been reported to be important in the etiology of GCa.

The Mucin 1 (MUC1) gene is a member of the mucin family encoding membrane-bound glycoproteins. The mucin 1 protein protects gastric epithelial cells from a variety of external insults that potentially cause inflammation, leading to carcinogenesis. Although MUC1 has 712 SNPs as reported to the dbSNP database (http://www.ncbi.nlm.nih.gov/projects/SNP/snp_ref.cgi?sh owRare $=$ on \& chooseRs $=$ all \&go $=$ Go\&locusId $=4582$ ), only 11 SNPs (Figure 1A.) have actually been confirmed in the HapMap database, of which only rs4072037 has a MAF $>0.05$, representing a block of 4 SNPs (Figure 1B). The rs4072037 A $>$ G polymorphism is located in the 5 ' untranslated region (UTR) of the second exon of MUC1 at chromosome 1q22, alters transcriptional regulation, and determines splice variants in MUC1 [9]. Several studies reported an association between the MUC1 rs4072037 $\mathrm{A}>\mathrm{G}$ polymorphism and GCa risk [10-16], but the results were inconclusive, especially different by ethnic group and primary tumor site. To further confirm this reported association, we conducted a replication study in an Eastern Chinese population with a relatively larger sample with subgroup analysis. Furthermore, a meta-analysis was also performed to further validate the association.
A

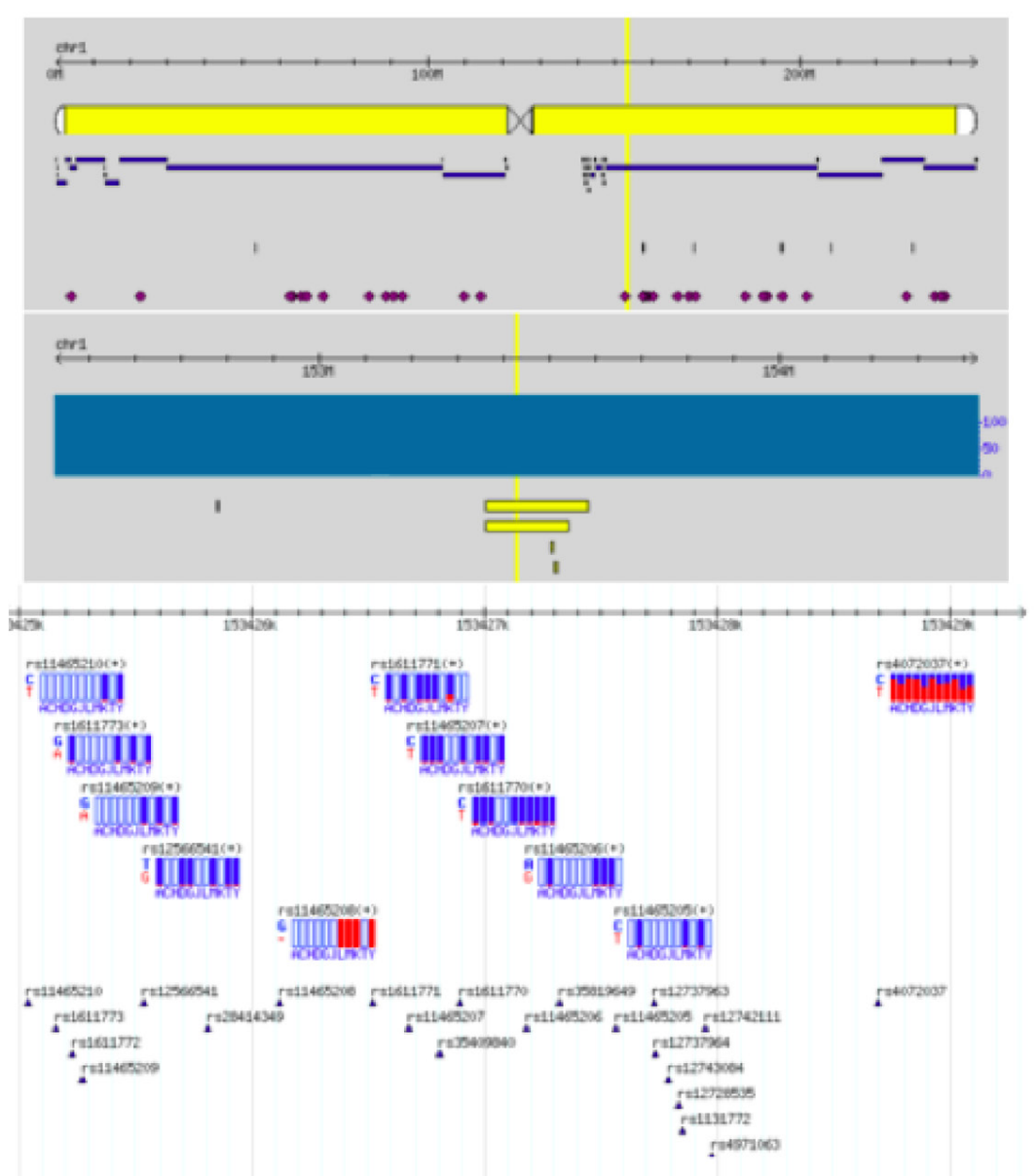

B

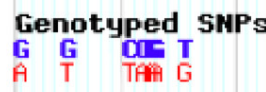

Entrez genes Ni1_025058

PRIM46: tripartite motif-containing 46 NM_001018016

MUD1: mucin 1 isoform 2 precurso NM_001018017

ㄱ-1-2-

MUL1: mucin 1 isoform 3 precurso NM_001044390

工

MUL1: mucin 1 isoform 5 precurso NM_o01044391

ㄱ-1MUC1: mucin 1 isoform 6 precurso NM1_001044392

DI-_MUC1: mucin 1 isoform 7 precurso NM_001044393

-

MUC1: mucin 1 isoform 6 precurso NM_002456

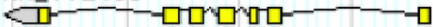
MUL1: mucin 1 isoform 1 precurso

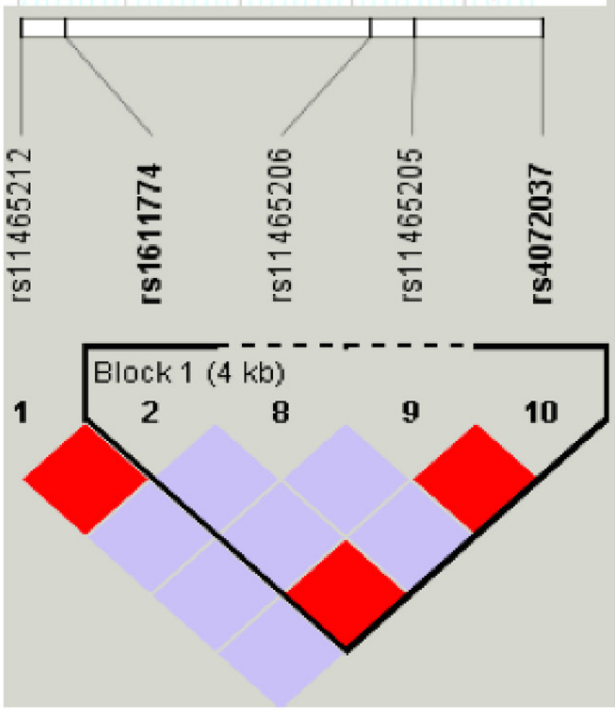

Figure 1: Reported MUC1 SNPs. Although MUC1 has 712 SNPs as reported to the dbSNP database, only 11 SNPs (A) with genotypes are actually confirmed in the HapMap database, of which only rs4072037 has a MAF > 0.05, representing a block of 4 SNPs (B). 


\section{RESULTS}

The characteristics of participants included in this hospital-based case-control study were described elsewhere [17], but one sample in cases and four samples in controls failed to be genotyped in the current study. Thus, the final analysis included 1,124 GCa cases and 1,192 cancerfree controls. Participants were well matched by age and sex with more smokers and drinkers in the controls, but these variables were further adjusted in the following multivariate analysis.

Table 1 lists allele frequencies of the rs 4072037 A $>$ G SNP in cases and controls and the estimated association between this SNP and GCa risk. Overall, the G allele was associated with a decreased GC risk in the study population [GG vs. AA, $\mathrm{OR}=0.47,95 \% \mathrm{CI}=0.31-0.73$; $\mathrm{AG} / \mathrm{GG}$ vs. $\mathrm{AA}, \mathrm{OR}=0.82,95 \% \mathrm{CI}=0.68-0.99$; GG vs. $\mathrm{AA} / \mathrm{AG}, \mathrm{OR}=0.48,95 \% \mathrm{CI}=0.32-0.74]$. In the stratified analysis (Table 2), these associations remained significant in subgroups of age, tumor site, drinking and smoking status.

Then, we performed a mini meta-analysis, including the present study, of eight studies with 7312 cases and 6112 controls [10-16]. The pooled data indicated that the $\mathrm{G}$ allele was strongly associated with a decreased GCa risk (Table 3: AG vs. AA: $\mathrm{OR}=0.64,95 \% \mathrm{CI}=0.54-0.77$; $\mathrm{GG}$ vs. $\mathrm{AA}$ : $\mathrm{OR}=0.55,95 \% \mathrm{CI}=0.46-0.65 ; \mathrm{AG} / \mathrm{GG}$ vs. $\mathrm{AA}: \mathrm{OR}=0.63$, $95 \% \mathrm{CI}=0.53-0.75$, Figure 2 ; and GG vs. AA/AG: $\mathrm{OR}=$
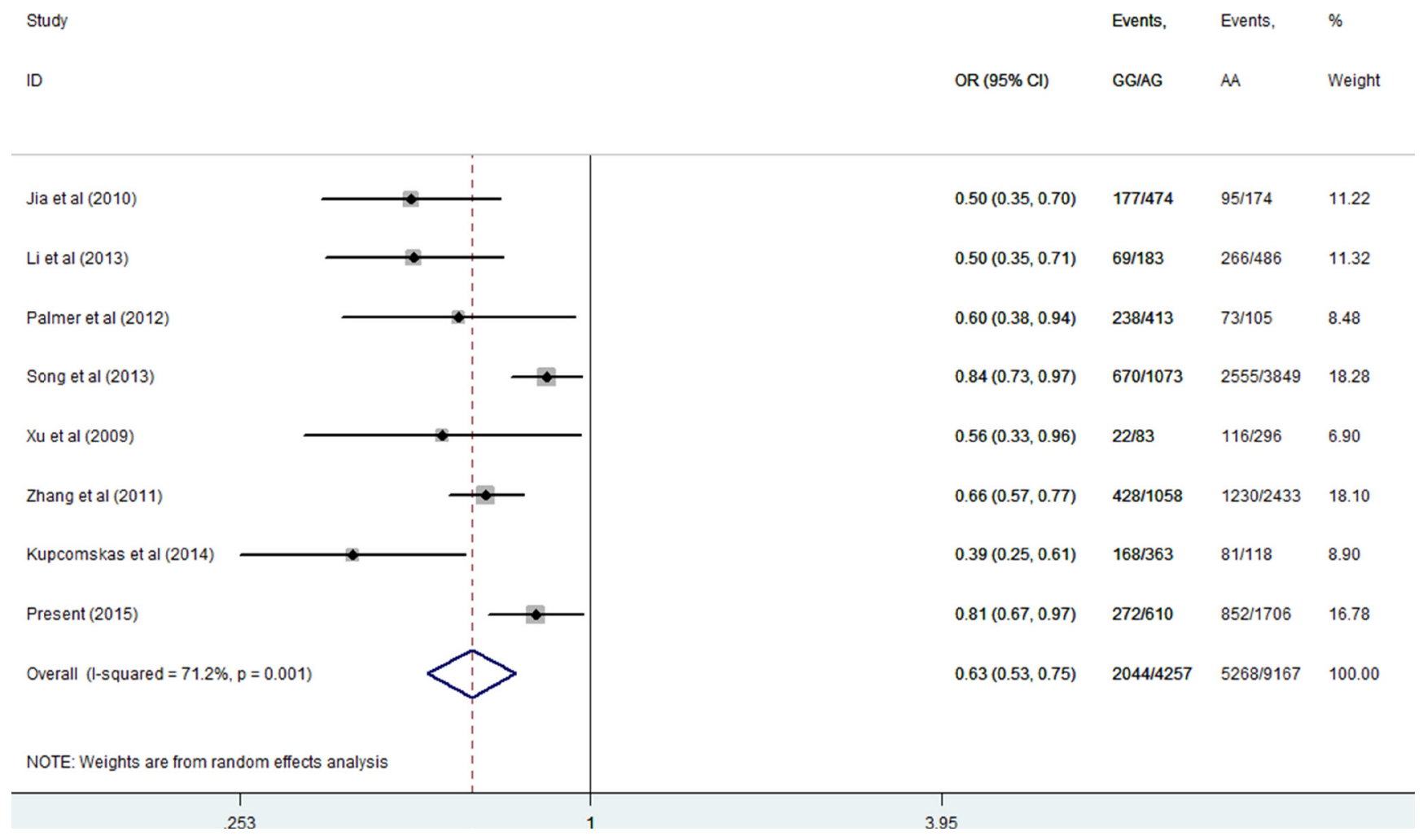

Figure 2: Meta-analysis for the association between $M U C 1$ rs4072037 SNP and GCa risk in the dominant genetic model (random-effects model).
$0.72,95 \% \mathrm{CI}=0.62-0.84$, Figure 3) without significant publication bias. However, significant heterogeneities across studies were present in these genetic models. Thus, we performed a sensitivity analysis to assess the effects of each study on the pooled results. The pooled ORs were not affected by omitting each of studies at a time (data not shown), which suggests that the overall results are robust.

\section{DISCUSSION}

In addition to environmental and lifestyle factors for GCa risk, genetic factors are also important in identifying at-risk populations for primary prevention of GCa. The results presented here consistently showed that the $\mathrm{G}$ allele of the $M U C 1$ rs4072037 A > G SNP was associated with a decreased risk of GCa. This SNP located in the $5^{\prime}$ UTR of the second exon is predicted to have an effect on the splicing of the primary transcripts, which in turn determines the type of variants. Studies suggest that the $\mathrm{G}$ allele results in the expression of variant 2 , while the A allele results in the expression of variant $3[9,24]$. The structural difference between these two variants leads to insertion/deletion of nine amino acids encoded by the second exon, which are involved in the N-terminal signal peptide. This differential signal peptide may lead to a different function of the encoded variant protein. Also, the A allele reduces the transcriptional activity, which may result in decreased MUC1 expression [9]. Furthermore,

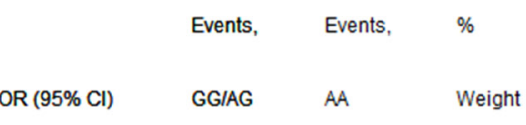


Table 1: Logistic regression analysis of associations between the genotypes of $M U C 1$ rs4072037 $A>G$ and gastric cancer risk in an Eastern Chinese population

\begin{tabular}{|c|c|c|c|c|c|c|c|}
\hline Genotype & $\begin{array}{c}\text { Cases } \\
(N=1,124)\end{array}$ & $\begin{array}{c}\text { Controls } \\
(N=1,192)\end{array}$ & $P^{a}$ & $\begin{array}{c}\text { Crude } \\
\text { OR }(95 \% \text { CI })\end{array}$ & $P$ & $\begin{array}{c}\text { Adjusted } \\
\text { OR }(95 \% \text { CI })^{b}\end{array}$ & $P^{b}$ \\
\hline \multicolumn{8}{|c|}{ MUC1 rs4072037 } \\
\hline $\mathrm{AA}$ & $852(75.8)$ & $854(71.6)$ & $0.002^{\mathrm{c}}$ & 1.00 & & 1.00 & \\
\hline $\mathrm{AG}$ & $240(21.4)$ & $270(22.7)$ & & $0.89(0.73-1.09)$ & 0.253 & $0.91(0.74-1.11)$ & 0.328 \\
\hline $\mathrm{GG}$ & $32(2.8)$ & $68(5.7)$ & & $0.47(0.31-0.73)$ & 0.0006 & $0.47(0.31-0.73)$ & 0.0007 \\
\hline $\mathrm{AG} / \mathrm{GG}$ & $272(24.2)$ & $338(28.4)$ & $0.023^{\mathrm{d}}$ & $0.81(0.67-0.97)$ & 0.023 & $0.82(0.68-0.99)$ & 0.035 \\
\hline Additive & & & & $0.79(0.68-0.92)$ & 0.002 & $0.80(0.68-0.93)$ & 0.003 \\
\hline $\mathrm{AG} / \mathrm{AA}$ & $1092(97.2)$ & $1124(74.2)$ & & 1.00 & & 1.00 & \\
\hline GG & $32(2.8)$ & $68(5.7)$ & $0.0007^{\mathrm{e}}$ & $0.48(0.32-0.74)$ & 0.0009 & $0.48(0.32-0.74)$ & 0.0009 \\
\hline
\end{tabular}

CI, confidence interval; OR, odds ratio.

${ }^{\mathrm{a}} \mathrm{Chi}$ square test for genotype distributions between cases and controls.

${ }^{\mathrm{b}}$ Adjusted for age, sex, smoking and drinking status in logistic regression models.

cfor additive genetic models.

dfor dominant genetic models.

efor recessive genetic models.

Table 2: Stratification analysis for the association between $M U C 1 \mathrm{rs4072037} \mathrm{A}>\mathrm{G}$ polymorphism and GC risk in an Eastern Chinese population

\begin{tabular}{|c|c|c|c|c|c|c|}
\hline \multirow{2}{*}{ Variables } & \multicolumn{2}{|c|}{ rs4072037 (cases/controls) } & \multirow{2}{*}{$\begin{array}{c}\text { Crude } \\
\text { OR }(95 \% \text { CI })\end{array}$} & \multirow{2}{*}{$P$} & \multirow{2}{*}{$\begin{array}{c}\text { Adjusted } \\
\mathrm{OR}^{\mathrm{a}}(95 \% \mathrm{CI})\end{array}$} & \multirow{2}{*}{$P^{a}$} \\
\hline & AG/AA & GG & & & & \\
\hline \multicolumn{7}{|l|}{ Median age, yr } \\
\hline$\leq 59$ & $564 / 574$ & $14 / 32$ & $0.45(0.24-0.84)$ & 0.013 & $0.45(0.24-0.85)$ & 0.014 \\
\hline$>59$ & $528 / 550$ & $18 / 36$ & $0.52(0.29-0.93)$ & 0.027 & $0.51(0.28-0.91)$ & 0.023 \\
\hline \multicolumn{7}{|l|}{ Sex } \\
\hline Males & $779 / 773$ & $21 / 52$ & $0.40(0.24-0.67)$ & 0.0005 & $0.40(0.24-0.68)$ & 0.0006 \\
\hline Females & $313 / 351$ & $11 / 16$ & $0.77(0.35-1.69)$ & 0.515 & $0.81(0.37-1.78)$ & 0.591 \\
\hline \multicolumn{7}{|l|}{ Smoking status } \\
\hline Never & $664 / 574$ & $21 / 32$ & $0.57(0.32-1.00)$ & 0.048 & $0.55(0.31-0.98)$ & 0.041 \\
\hline Ever & $428 / 550$ & $11 / 36$ & $0.39(0.20-0.78)$ & 0.008 & $0.40(0.20-0.81)$ & 0.010 \\
\hline \multicolumn{7}{|l|}{ Pack-year } \\
\hline 0 & $664 / 574$ & $21 / 32$ & $0.57(0.32-1.00)$ & 0.048 & $0.55(0.31-0.98)$ & 0.041 \\
\hline$\leq 25$ (mean) & $222 / 332$ & $5 / 21$ & $0.36(0.13-0.96)$ & 0.041 & $0.36(0.13-0.97)$ & 0.044 \\
\hline$>25$ (mean) & $206 / 218$ & $6 / 15$ & $0.42(0.16-1.11)$ & 0.081 & $0.48(0.18-1.27)$ & 0.137 \\
\hline \multicolumn{7}{|l|}{ Drinking status } \\
\hline Never & $828 / 804$ & $26 / 44$ & $0.57(0.35-0.94)$ & 0.028 & $0.57(0.35-0.94)$ & 0.027 \\
\hline Ever & $264 / 320$ & $6 / 24$ & $0.30(0.12-0.75)$ & 0.010 & $0.31(0.12-0.77)$ & 0.011 \\
\hline \multicolumn{7}{|l|}{ Tumor site } \\
\hline GCA & $297 / 1124$ & $8 / 68$ & $0.45(0.21-0.94)$ & 0.033 & $0.42(0.20-0.89)$ & 0.024 \\
\hline NGCA & $795 / 1124$ & $24 / 68$ & $0.50(0.31-0.80)$ & 0.004 & $0.50(0.31-0.81)$ & 0.005 \\
\hline
\end{tabular}

${ }^{a}$ Adjusted for age, sex, smoking and drinking status in logistic regression models. 
Table 3: Meta-analysis for the association between the $M U C 1$ rs4072037 A > G SNP and GCa risk

\begin{tabular}{|l|c|c|c|c|c|c|c|c|}
\hline \multicolumn{1}{c}{ Genotype } & $\begin{array}{l}\text { No. of } \\
\text { Studies }\end{array}$ & No. of Cases & $\begin{array}{c}\text { No. of } \\
\text { Controls }\end{array}$ & OR (95\% CI) & \multicolumn{1}{c|}{$\boldsymbol{P}_{\text {heterogeneity }} \boldsymbol{I}^{\mathbf{2}}$ (\%) } & Model \\
\hline MUC1 rs4072037 & & & & & & & & \\
\hline AG vs AA & 8 & 6957 & 5677 & $0.64(0.54,0.77)$ & $P<0.001$ & 0.001 & $71.0 \%$ & Random \\
\hline GG vs AA & 8 & 5623 & 4334 & $0.55(0.46,0.65)$ & $P<0.001$ & 0.239 & $23.8 \%$ & Fixed \\
\hline AG/GG vs AA & 8 & 7312 & 6112 & $0.63(0.53,0.75)$ & $P<0.001$ & 0.038 & $71.2 \%$ & Random \\
\hline GG vs AA/AG & 8 & 7312 & 6112 & $0.72(0.62,0.84)$ & $P<0.001$ & 0.095 & $42.5 \%$ & Fixed \\
\hline
\end{tabular}

MUC1 can block the adhesion of HP blood group antigenbinding adhesion and sialic acid-binding adhesion to the gastric mucosa, which in turn limits the HP colonization $[25,26]$, and MUC1 acts as a barrier against exogenous insults in normal epithelial cells [25]. Therefore, low expression of MUC1 may cause a reduction in its barrier function in the stomach and subsequently increases $\mathrm{GCa}$ susceptibility. Such a hypothesis needs to be tested in additional mechanistic studies.

There are some limitations in the present study. First, although age, sex, smoking and drinking status, and tumor site were taken into consideration for subgroup analysis, other important risk factors, such as diet and HP infection, were missing in the study, which might also contribute to

Study

ID

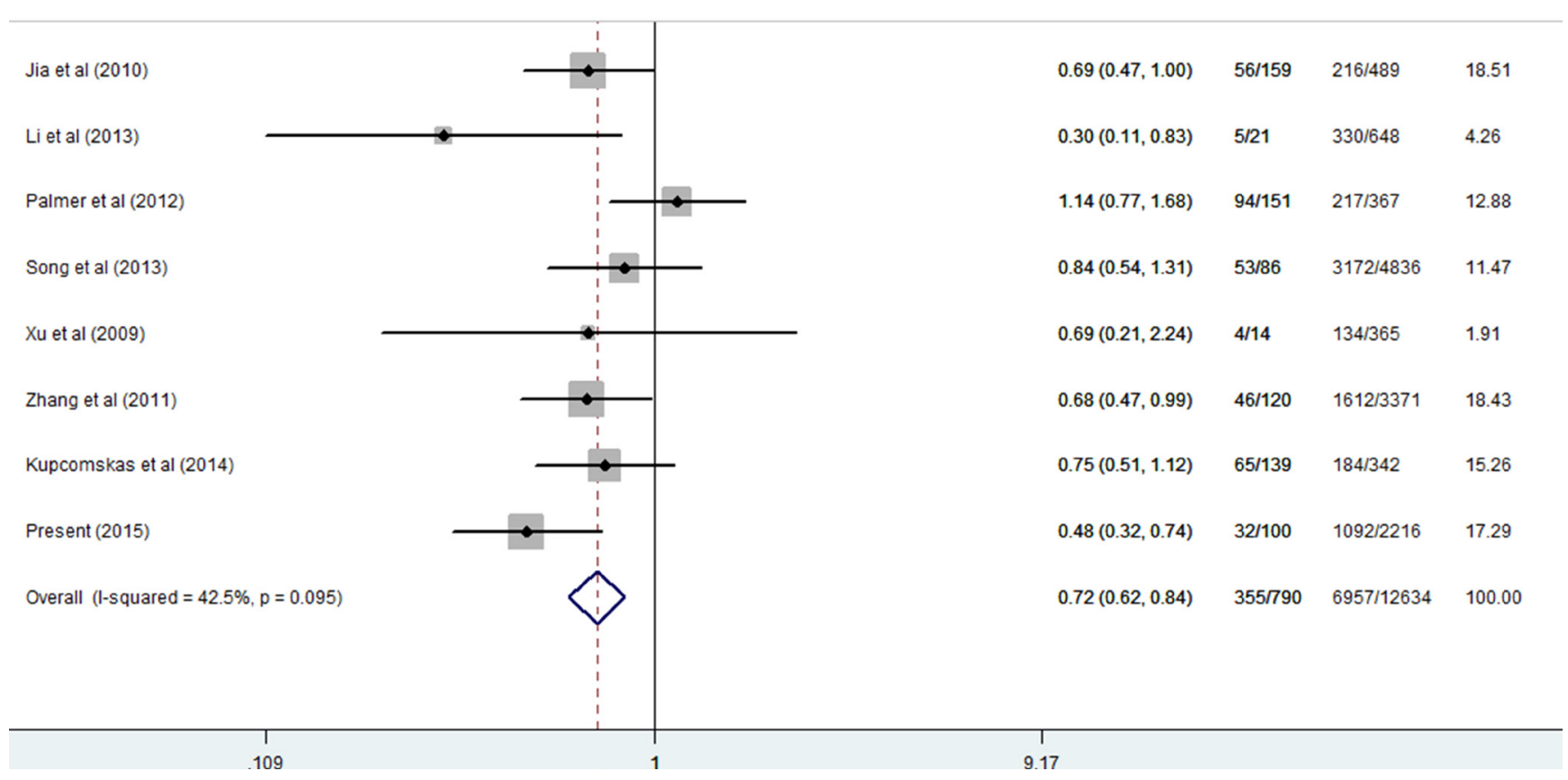

Figure 3: Meta-analysis for the association between $M U C 1$ rs4072037 SNP and GCa risk in the recessive genetic model (fixed-effects model). the etiology of GCa. Second, new classification of GCa tumor types, which was not available for the patients diagnosed years ago, is also important and may have a different genetic basis in the etiology. Third, the sample size of the cases in subgroups was largely reduced in the stratification analysis, which may lead to limited statistical power in subsequent analysis.

In conclusion, the present study confirmed that the G allele of the MUC1 rs4072037 SNP was a lowpenetrating protection factor for $\mathrm{GCa}$ risk. However, future studies should incorporate diet, $H P$ infection status and Lauren classification to better understand the associations between the MUC1 rs4072037 SNP and GCa susceptibility.
OR $(95 \% \mathrm{Cl}) \quad$ GG AANA Weight 


\section{METHODS}

\section{Study subjects}

This study included patients who were recruited from our ongoing molecular epidemiology study of GCa, and the cases and controls were described previously [17-19]. Briefly, 1,125 unrelated ethnic Han Chinese patients with newly diagnosed and histopathologically confirmed primary gastric cardia adenocarcinoma and nongastric cardia adenocarcinoma (NGCA) were recruited from Fudan University Shanghai Cancer Center (FUSCC) in Eastern China between January 2009 and March 2011. Patients other than histopathologically confirmed primary GCa were excluded. In addition, 1,196 age and sex-matched cancer-free ethnic Han Chinese controls were recruited from the Taizhou Longitudinal (TZL) study conducted at the same time period in Eastern China as described previously [20]. Blood samples from both GCa patients and cancer-free controls were provided by the tissue bank of FUSCC and the TZL study, respectively. All participants had signed a written informed consent for donating their biological samples to the tissue bank for scientific research. Demographic data and environmental exposure history of each participants were collected. The overall response rate was approximately $91 \%$ for cases and $90 \%$ for controls. This research protocol was approved by the FUSCC institutional review board.

\section{SNP genotyping}

According to a relevant protocol, we extracted genomic DNA from peripheral blood. The rs4072037 SNP was genotyped by the TaqMan assay with ABI7900HT real-time PCR system (Applied Biosystems) as reported previously [17]. Participants' status was unrevealed in the genotyping process. As recommend by the company, four negative controls (without DNA templates) and two duplicated samples were included in each 384-plate for the quality control. The assays were repeated for $5 \%$ of the samples, and the results were $100 \%$ concordant.

\section{Statistical methods}

The $\chi^{2}$ test was used to assess differences in the distributions of demographic characteristics between cases and controls. The association between SNP and GCa risk was assessed by odds ratio (OR) and $95 \%$ confidence intervals (CIs) in heterozygous (AG vs AA), homozygous (GG vs $A A)$, dominant ( $A G+G G$ vs $A A)$, recessive (GG vs $A G+A A)$, and additive (G vs A) models, respectively. OR values were calculated by both univariate and multivariate logistic regression models. Moreover, logistic regression tests for each genetic model were adjusted for age, sex, drinking and smoking status. Furthermore, the association between the MUC1 rs4072037 SNP and GCa risk was also stratified by age, sex, smoking or drinking status, and primary tumor site. All statistical process above was achieved by SAS software (version 9.1; SAS Institute, Cary, NC)

To validate the results of the present study, we performed a mini meta-analysis with studies searched from Medline, PubMed and Embase. After using the search terms and inclusion and exclusion criteria as described in previous studies [21, 22], all primary reports were carefully reviewed, and the relevant references in these papers were also searched and reviewed by two independent authors. Then, data were retrieved from the reported studies and pooled crude ORs for heterozygous, homozygous, dominant, and recessive models were calculated. Heterogeneity between studies was estimated by Chi-square-based $Q$ test. Pooled ORs were calculated by a fixed- or random-effects model, depending on the heterogeneity between searched studies [23]. To validate the stability of the pooled results and to identify the sources of heterogeneity, the leave-one-out sensitive analysis was performed. Publication bias was shown by the funnel plot, in which the asymmetry was estimated by the Egger's liner regression test, where the statistically significant publication bias was tested, when $P<0.05$ determined by the $t$ test as suggested by Egger. All statistical process was achieved by STATA version 10.0 (Stata Corporation, College Station, TX).

\section{ACKNOWLEDGMENTS AND FUNDING}

This study was supported by grant from the National Natural Science Foundation of China (81101808, 81502046), the grant from "China's Thousand Talents Program" Recruitment at Fudan University, the Special Financial Grant from the China Postdoctoral Science Foundation (Grant No. 2014T70836), and the grant from the Ministry of Health (201002007).

\section{CONFLICTS OF INTEREST}

None declared.

\section{REFERENCES}

1. Torre LA, Bray F, Siegel RL, Ferlay J, Lortet-Tieulent J, Jemal A. Global cancer statistics, 2012. CA Cancer J Clin. 2015; 65:87-108.

2. Ye W, Held M, Lagergren J, Engstrand L, Blot WJ, McLaughlin JK, Nyren O. Helicobacter pylori infection and gastric atrophy: risk of adenocarcinoma and squamouscell carcinoma of the esophagus and adenocarcinoma of the gastric cardia. J Natl Cancer Inst. 2004; 96:388-396.

3. Ishaq S, Nunn L. Helicobacter pylori and gastric cancer: a state of the art review. Gastroenterol Hepatol Bed Bench. 2015; 8:S6-S14. 
4. Woo HD, Lee J, Choi IJ, Kim CG, Lee JY, Kwon O, Kim J. Dietary flavonoids and gastric cancer risk in a Korean population. Nutrients. 2014; 6:4961-4973.

5. Wang Z, Dai J, Hu N. Identification of new susceptibility loci for gastric non-cardia adenocarcinoma: pooled results from two Chinese genome-wide association studies. Gut. 2015; doi:10.1136/gutjnl-2015-310612.

6. Qiu LX, Cheng L, He J, Zhu XD, Wei QY. PSCA polymorphisms and gastric cancer susceptibility in an Eastern Chinese population. Oncotarget. 2016; Advance Publications. doi: 10.18632/oncotarget.7137.

7. Mocellin S, Verdi D, Pooley KA, Nitti D. Genetic variation and gastric cancer risk: a field synopsis and meta-analysis. Gut. 2015; 64:1209-1219.

8. Qiu LX, He J, Cheng L, Zhou F, Wang MY, Sun MH, Zhou XY, Li J, Guo WJ, Wang YN, Yang YJ, Wang JC, Jin L, et al. Genetic variant of PRKAA1 and gastric cancer risk in an Eastern Chinese population. Oncotarget. 2015; 6: 42661-426666. doi: 10.18632/oncotarget.6124.

9. Ng W, Loh AX, Teixeira AS, Pereira SP, Swallow DM. Genetic regulation of MUC1 alternative splicing in human tissues. Br J Cancer. 2008; 99:978-985.

10. Jia Y, Persson C, Hou L, Zheng Z, Yeager M, Lissowska J, Chanock SJ, Chow WH, Ye W. A comprehensive analysis of common genetic variation in MUC1, MUC5AC, MUC6 genes and risk of stomach cancer. Cancer Causes Control. 2010; 21:313-321.

11. Li M, Huang L, Qiu H, Fu Q, Li W, Yu Q, Sun L, Zhang L, Hu G, Hu J, Yuan X. Helicobacter pylori Infection Synergizes with Three Inflammation-Related Genetic Variants in the GWASs to Increase Risk of Gastric Cancer in a Chinese Population. PLoS One. 2013; 8:e74976.

12. Palmer AJ, Lochhead P, Hold GL, Rabkin CS, Chow WH, Lissowska J, Vaughan TL, Berry S, Gammon M, Risch H, ElOmar EM. Genetic variation in C20orf54, PLCE1 and MUC1 and the risk of upper gastrointestinal cancers in Caucasian populations. Eur J Cancer Prev. 2012; 21:541-544.

13. Song HR, Kim HN, Kweon SS, Choi JS, Shim HJ, Cho SH, Chung IJ, Park YK, Kim SH,Choi YD, Joo KW, Shin MH. Common genetic variants at 1q22 and 10q23 and gastric cancer susceptibility in a Korean population. Tumour Biol. 2014; 35:3133-3137.

14. Xu Q, Yuan Y, Sun LP, Gong YH, Xu Y, Yu XW, Dong NN, Lin GD, Smith PN, Li RW. Risk of gastric cancer is associated with the MUC1 $568 \mathrm{~A} / \mathrm{G}$ polymorphism. Int J Oncol. 2009; 35:1313-1320.

15. Zhang HZ, Jin G, Li H, Ren C, Ding Y, Zhang Q, Deng B, Wang J, Hu Z, Xu Y, Shen H. Genetic variants at 1q22 and $10 \mathrm{q} 23$ reproducibly associated with gastric cancer susceptibility in a Chinese population. Carcinogenesis. $2011 ; 32: 848-852$.
16. Kupcinskas J, Wex T, Link A, Bartuseviciute R, Dedelaite M, Kevalaite G, Leja M, Skieceviciene J, Kiudelis G, Jonaitis L, Kupcinskas L, Malfertheiner P. PSCA and MUC1 gene polymorphisms are associated with gastric cancer and premalignant gastric conditions. Anticancer Res. 2014; 34: $7167-7175$.

17. He J, Qiu LX, Wang MY, Hua RX, Zhang RX, Yu HP, Wang YN, Sun MH, Zhou XY, Yang YJ, Wang JC, Jin L, Wei QY, et al. Polymorphisms in the XPG gene and risk of gastric cancer in Chinese populations. Hum Genet. 2012; 131:1235-1244.

18. He J, Xu Y, Qiu LX, Li J, Zhou XY, Sun MH, Wang JC, Yang YJ, Jin L, Wei QY, Wang Y. Polymorphisms in ERCC1 and XPF genes and risk of gastric cancer in an Eastern Chinese population. PloS one. 2012; 7:e49308.

19. He J, Wang MY, Qiu LX, Zhu ML, Shi TY, Zhou XY, Sun MH, Yang YJ, Wang JC, Jin L, Wang YN, Li J, Yu HP, et al. Genetic variations of mTORC1 genes and risk of gastric cancer in an Eastern Chinese population. Mol Carcinog. 2013; 52:E70-79.

20. Wang X, Lu M, Qian J, Yang Y, Li S, Lu D, Yu S, Meng W, Ye W, Jin L. Rationales, design and recruitment of the Taizhou Longitudinal Study. BMC Public Health. 2009; 9:223.

21. Qiu LX, Zhang J, Zhu XD, Zheng CL, Sun S, Wang ZH, Zhao XM, Wang JL, Wang LP, Yu H, Xue K, Hu XC. The p21 Ser31Arg polymorphism and breast cancer risk: a metaanalysis involving 51,236 subjects. Breast Cancer Res Treat. 2010; 124:475-479.

22. Zhu J, Wang M, Zhu M, He J, Wang JC, Jin L, Wang XF, Xiang JQ, Wei Q. Associations of PI3KR1 and mTOR polymorphisms with esophageal squamous cell carcinoma risk and gene-environment interactions in Eastern Chinese populations. Sci Rep. 2015; 5:8250-8256.

23. Zintzaras E, Ioannidis JP. Heterogeneity testing in metaanalysis of genome searches. Genet Epidemiol. 2005; 28:123-137.

24. Saeki N, Saito A. A functional single nucleotide polymorphism in mucin 1, at chromosome 1q22, determines susceptibility to diffuse-type gastric cancer. Gastroenterology. 2011; 140:892-902.

25. Linden SK, Sheng YH, Every AL, Miles KM, Skoog EC, Florin TH, Sutton P, McGuckin MA. MUC1 limits Helicobacter pylori infection both by steric hindrance and by acting as a releasable decoy. PLoS Pathog. 2009; 5:e1000617.

26. Skoog EC, Sjoling A, Navabi N, Holgersson J, Lundin SB, Linden SK. Human gastric mucins differently regulate Helicobacter pylori proliferation, gene expression and interactions with host cells. PLoS One. 2012; 7:e36378. 